Perhaps the Royal College of Psychiatrists and the British Journal of Psychiatry, and other interested parties, could collaborate with Asylum and the survivors' movements etc. to initiate conferences or symposia run by users and workers to explore some of the issues outlined above. Both undergraduate and postgraduate training, in our view, should involve some time spent considering, and perhaps even testing, the political and social issues involved in psychiatric practice and the rhetorical and theoretical justifications for such practices. We believe that there should be a curriculum for the training of psychiatrists that is influenced by user groups. To be able to deal with such varied inputs, psychiatrists would need some background training in political and social studies and philosophy, and they should be strongly encouraged to develop a critical faculty. Not one of us can see clearly our position in the world of psychiatry and psychiatric practice, but what we can do is to see dangers and approach such dangers with courage and a real desire to sort these things out. Psychiatrists need to have a grounding in 'problematics'.

It is unfortunate that many patients and patient groups, not unreasonably, believe that doctors see themselves as almost infallible. Patients frequently experience doctors diagnosing them as fundamentally different from the rest of society and fundamentally different from the doctor. Many doctors believe this too. More unfortunately, doctors are often quite unaware of the effects of what they do in terms of patients' lives, feelings and activities.

When Peter Tyrer says that the user movement "in psychiatry is now a healthy and aggressive toddler, but if we ignore its development it could well show signs of delinquency", we hope we understand him correctly. Blind indifference and calculated ignorance will be as damaging as active opposition to the users' movements; patients engaging in battle with psychiatrists is perhaps a mass sickness that psychiatrists really could cure.

T. J. G. KENDALL F. A. JENNER

Royal Hallamshire Hospital Sheffield S10 2JF

\section{Residential units for families}

DeAr SirS

'The Treatment of Child Abuse in an In-patient Setting' (Bulletin, September 1988, 12, 361-366) brings to light the possibility of offering help to families that are difficult to help in the conventional outpatient and community settings. The Cassel Hospital unit, however, is not the only medical establishment with in-patient beds for whole families (Brendler, 1987; Haldon et al, 1980; Lynch et al, 1975). In
Portsmouth we have two such units, one of which has been in operation for 14 years, and it caters for families which need intensive treatment over long periods of time. The other one caters for families that need intensive treatment over shorter periods of time.

Our units cater for a wide spectrum of emotional problems; behavioural disorders, emotional deprivation, severe multiple non-accidental injuries, childhood psychosis, adult psychosis infanticide, children at risk of non-accidental injury, multiple problem families, intractable cases of enuresis and encopresis. The duration of hospitalisation in the long term unit varies from two months to 18 months with an average stay of five months, and in the short term unit, from three weeks to 12 weeks with an average stay of seven weeks.

The treatment programme in our units is similar to that described at the Cassel Hospital but with the emphasis on team assessment based on preadmission one day assessment and one to four weeks assessment/observation in hospital. The treatment programme is tailored for each family and treatment methods include family therapy, individual therapy for adults, individual/play therapy for children, behavioural therapy, parent's group, video feedback, art therapy, marital counselling, information/ education, activities of daily living, medications, hypnotherapy, dance therapy and regression therapy. We maintain close liaison with the community network.

Attachment theory (Bowlby, 1969; 1973) is found useful, both in understanding and helping families. If we understand parents as people who fail to make secure bonds with their own attachment figures and are consequently unable to be adequte attachment figures for their own children, then we strengthen the parents enough so they can become the attachment figures for the children. At the same time we work with the children to make them amenable to bonding to their parents. If we fail to strengthen the parents then we try to get the children to attach to the staff in the unit and then transfer the attachment to a foster/adoptive family.

We agree that treating such families is a long-term investment for society in that it saves resources that would have to be spent on fostering, children's homes, legal circles and drainage of the health resources. Even in cases where the outcome is separating the children from the parents, our continued support for the children to settle in new families and for the parents to let go of the children helps to cut the cycle of deprivation.

We agree that it is difficult to predict which families will benefit most from such treatment. In our unit it is intuitive, and if as a team we feel we have something to offer we try. It is not scientific but we make no apology. 
Working in such units is emotionally demanding and needs sophisticated training. It is difficult to assess the value of units like these because of the inherent problems in research in family therapy (Frude, 1980), but perhaps we have to lower our expectations methodologically to evaluate the effectiveness of family therapy (Lask, 1988), in particular with family work done in residential units where the variables are even more complex.

The trend is rightly towards working in the community. However, certain families' needs are beyond what can be offered in an out-patient or community setting. In-patient units can provide hope and help for such families. Although these units are residential, their work is for the community and uses community networks.

King Faisal Military Hospital

A. K. DARWISH

PO Box 101, Khamis Mushayt Saudi Arabia

\section{References}

BowlBy, J. (1969) Attachment and Loss, 1: Attachment, London: Hogarth Press.

- (1973) Attachment and Loss, 3: Separation, Anxiety and Anger, London: Hogarth Press.

BRENDLER, J. (1987) A perspective on brief hospitalisation of whole familes. Journal of Family Therapy, 9, 113-130.

FrUDE, N. (1980) Methodological problems in the evaluation of family therapy. Journal of Family Therapy, 2 , 29-44.

Haldan, J. D., McCluskey, U. \& Peacey, M. (1980) Development of a residential facility for families in Scotland: Prospect and retrospect. International Journal of Family Psychiatry, 1, 357-371.

LASK, B. (1988) Family therapy research. A challenge and a proposal; Psychiatric Bulletin, 12, 489-490.

LYNCH, M., STEINBERG, D. \& OUNSTEAD, C. (1975) Family Units in a children's psychiatric hospital. British Medical Journal, 2, 127-129.

\section{Schizophrenia in ethnic minorities}

\section{DeAr Sirs}

It was heartening to read that Dr Glyn Harrison accepts the need for caution and sensitivity in researching psychiatric disorders and ethnic groups (Psychiatric Bulletin, May 1989). Unfortunately he appears to have read into my letter (Psychiatric Bulletin, May 1989) ideas that were not there and missed most of the points that I did make. I did not object to research aimed at discovering the reasons for the relatively excessive diagnosis of schizophrenia that is given to black people; nor did I call for a 'censorship' of research into this matter. I drew attention to certain important aspects of the concept of schizophrenia, the disadvantages to American Blacks that resulted from the publication of the paper on IQ by Jensen (1969) and the potential dangers inherent in the paper by Harrison et al. (1988). In this context, I called for sensitive systems for evaluating papers concerned with racial and cultural issues so that their overall worth might be assessed.

The main objections to the paper by Harrison $\dot{e} t$ al (1988) may be summarised as follows: The research method ignored the pitfalls of cross-cultural diagnosis in a racist society and failed to confront, or even recognise, the facts concerning racism in psychiatry described elsewhere (Fernando, 1988); consequently, a lopsided picture of the overdiagnosis of schizophrenia among black people was presented in the paper and discussed in terms of the 'incidence' of a biologically determined illness. This left the paper wide open for the general public and the media to use for the purpose of reinforcing racist stereotypes and myths. And this is exactly what has happened so far vide the press report in The Guardian on 31 October 1988 (page 6) headlined 'Young blacks vulnerable to schizophrenia' and the BBC Horizon Programme called 'Black Schizophrenia' broadcast on 13 March 1989.

Dr Harrison gives his personal opinion that genetic factors are relatively unimportant in relation to the higher rates of (the diagnosis of) psychoses in AfroCaribbeans, although he does not say to whose genetics he is referring. But the discussion in the Nottingham paper gives a different impression; genetic and/or constitutional vulnerability is quoted no less than four times - and it is the genetics of black people that apparently arouse the interest of the authors. In contrast to this, the discussion in their paper does not raise cultural and racial issues at all; for example, there is no reference to the fact that the concept of schizophrenia used by the researchers is one derived and refined in white European populations; no attempt is made to describe what knowledge, if any, the researchers have of black life experiences, religions and lifestyles; and no recognition is given to the problems arising from conducting interviews in a racist society.

Dr Harrison is correct in implying that psychiatry has a tradition of racism; what he may fail to appreciate is that racism is institutionalised in ways of working in psychiatry including its research methodology, in addition to being a major part of the life experiences of black people. Reports of psychiatric research into the diagnosis of schizophrenia in black people that ignores the reality of racism cannot possibly claim to be worthy of publication and certainly cannot be considered useful. And it is not 'scientific' to ignore reality.

My view is that when papers concerned with racial and cultural matters are presented for publication, the assessment of their scientific worth and usefulness must be broad-based. Using the yardstick of 